Literature Reviews

\title{
Foot Pain in High Heels Woman users: Systematic Literature Review and Meta-Analysis
}

\author{
${ }^{1}$ Anisa Ferli Yolanda, ${ }^{2}$ Swandito Wicaksono and ${ }^{3 *}$ Ahmad Azmi Nasution \\ ${ }^{1}$ Faculty of Medicine and Health Sciences, Universitas Bengkulu, Bengkulu, Indonesia \\ ${ }^{2}$ Deparment of Physiology, Faculty of Medicine and Health Sciences, Universitas Bengkulu, Bengkulu, Indonesia \\ ${ }^{3}$ Departement of Anatomy, Faculty of Medicine and Health Sciences, Universitas Bengkulu, Bengkulu, Indonesia
}

\author{
Article history \\ Received: 15-09-2020 \\ Revised: $25-11-2020$ \\ Accepted: 30-11-2020 \\ Corresponding Author: \\ Ahmad Azmi Nasution \\ Departement of Anatomy, \\ Faculty of Medicine and Health \\ Sciences, Universitas \\ Bengkulu, Bengkulu, Indonesia \\ Email: ahmadazminasution@unib.ac.id
}

\begin{abstract}
In recent years, many women wear high heels. Wearing high heels that exceed the recommended usage of a maximum of three hours can harm the foot and body. Someone who suffers from foot pain will have a significant physical disability, difficulty in daily activities and an increase in falls and injuries. Thus far, there has been no meta-analysis study that strengthens the effect of wearing high heels on foot pain. Therefore, the author aimed to examine and determine whether there is an effect between wearing high-heeled shoes and foot pain problems. In searching literature review/literature studies, the author used a research database of PubMed and Trip database. The author also registered and installed publications more than one or duplicate, did abstracts screening, publications selection related to inclusion criteria and assessed the quality of studies using a developing Center for Evidence-Based Medicine (CEBM) tool. Of the 220 publications identified and after systematic literature screening, three data were used for meta-analysis. Comprehensive Meta-analysis software was used for statistical analysis. The effect of wearing high heels on foot pain is not statistically significant $(p=0.248)$, yet clinically the racial odds were 1.87. This result shows that woman who wears high heels has a risk of 1.87 times more likely to have foot pain.
\end{abstract}

Keywords: Woman, High Heels, Foot Pain

\section{Introduction}

Initially, footwear was used by humans as a cover and protector of their feet. However, recently footwear is now designed to meet various life goals, one of which is to make it more attractive (Buldt and Menz, 2018). In recent years, many women prefer high heels to flat shoes to make them look taller, sleeker and more fashionable (Edwards et al., 2008). In the results of a field study conducted by Maarouf, $68 \%$ of women preferred wearing high heels. Wearing high heels make female more confidence and attractive because of taller than as usual. At particular events, $88 \%$ of women prefer wearing high heels (Maarouf, 2015).

The wear of high heels, which exceeds the recommended usage of a maximum of three hours, can harm the foot and body (Ghiftama and Hakim, 2019). Epidemiological studies discussing foot pain in the elderly found that women have foot pain more often than men (Benvenuti et al., 1995). Foot pain causes physical disability and difficulty in daily activities. Hence, it increases the probability of falling and injuries. Foot pain harms the woman's quality of life (Stewart et al., 2003; Rao et al., 2012).

There have been several studies that discussed the effect of using high heels on foot pain. A controlled cohort study involving women aged 40-66 years showed $42 \%$ of women had pain due to the use of high heels for more than five years, while $28 \%$ of women also had pain despite not wearing high heels for five years (Borchgrevink et al., 2016). Case-control studies of 50-89 years old women showed no relationship between the use of high heels and foot pain (Menz et al., 2016).

According to several studies that have been done, the answers remain unclear whether the use of high heels affects foot pain. Therefore, the author did a systematic literature review and provided an evidence-based summary through a meta-analysis, whether there is an effect of wearing high-heeled shoes to foot pain. There have been no meta-analysis studies that strengthen the effect of using high heels on foot pain so far. 


\section{Methods}

Scope of Review: Criteria for Inclusion and Exclusion

\section{Inclusion Criteria:}

1) Articles must be original research articles that use primary data (not a literature review) and contain empirical elements

2) The study should focus on the effect of wearing high heels on foot pain in women

3) The study should be in English

4) The study must be in the last decade

5) Compare foot pain and non-foot pain on those who wear high heels

\section{Exclusion Criteria:}

1) Biomechanical simulation research

2) Research in students

\section{Data Collecting and Analysis}

The literature review is based on three databases, i.e., PubMed, Cochrane and Tripdatabase. Keywords used in literature were women, female, high heels, high heeled, footwear, foot pain, heel pain, plantar fasciitis. Boolean operators "AND" and "OR" are used to combine search keywords related to the questions. Determine the inclusion and exclusion criteria for publication obtained. Listed and deleted publications that were more than one or duplicated, did abstracts screening and chose publications that met the inclusion criteria. The author reviewed the title and abstract to determine whether the publication was included full-text screened. Analyzing data begins when data collection takes place.

The selected studies were then critically appraised for their validity, importance and applicability, according to the Central for Evidence-Based Medicine (CEBM) appraisal tool. Then the authors analyzed the Odds Ratio (OR) and the $95 \%$ Confidence Interval (CI) using the meta-analysis in tabular and figure form. Comprehensive Meta-analysis was used for statistical analysis.

\section{Result}

The 2009 flow chart prism was used to facilitate data extraction (Fig. 1). Research data were collected from two data centers, i.e., PubMed and trip database. Based on the entered PICO, the total number of publications collected data was 220. However, 76 publications with the same title were removed. Further, the publications were sorted based on predetermined inclusion criteria. One hundred thirty-four publications did not meet the inclusion criteria and only 10 data met the criteria. After that, a screening of the title was done. Three titles were relevant and used for the meta-analysis; whereas, six titles were excluded after reading the entire text. The study was focused on the effect of wearing high-heeled shoes on foot pain; it did not focus on the effect of using high heels on foot pain and did not compare between leg pain and non-leg pain in those who wear high heels.

\section{Study Characteristic}

The study design of the literature inserted in this study consisted of cross-sectional, case-control and controlled cohort studies.

\section{Study Quality Appraisal}

The quality appraisal of selected literature was done using the Central for Evidence-Based Medicine (CEBM) checklist (Table 1).

\section{Effect of Wearing High Heels on Foot Pain}

The study conducted by (Chua et al., 2013) defined high-heels as footwear with heels $>1$ inch $(2.5 \mathrm{~cm})$, while the study was conducted by (Borchgrevink et al., 2016) used the definition of footwear with heels $5 \mathrm{~cm}$ or higher. Both of these studies (controlled cohort and crosssectional) mentioned a statistically significant relationship between the use of high heels and foot pain (Chua et al., 2013; Borchgrevink et al., 2016). Other studies with a case-control study conducted by (Menz et al., 2016) showed that there was no relationship between the height of high-heeled shoes on foot pain in the last 12 months.

Table 1: A quality appraisal of the literature that meets the inclusion criteria $\sqrt{ }=$ Yes; $x=$ No;? $=$ Not clear

$\begin{array}{llll} & (1) & (2) \\ \text { Was a qualitative approach appropriate? } & \sqrt{ } & \sqrt{ } \\ \text { Was the sampling strategy appropriate for the approach? } & \sqrt{ } & \\ \text { What were the data collection methods? } & \sqrt{ } & \sqrt{ } \\ \text { How were data analyzed and how were these checked? } & \sqrt{ } & \sqrt{ } \\ \text { Is the researcher's position described? } & \sqrt{ } & \sqrt{ } \\ \text { Do the results make sense? } & \sqrt{ } & \sqrt{ } \\ \text { Are the conclusions drawn justified by the study? } & \sqrt{ } & \sqrt{ } \\ \text { Are the finding transferable to other clinical settings? } & \sqrt{ } & \sqrt{ } \\ \end{array}$




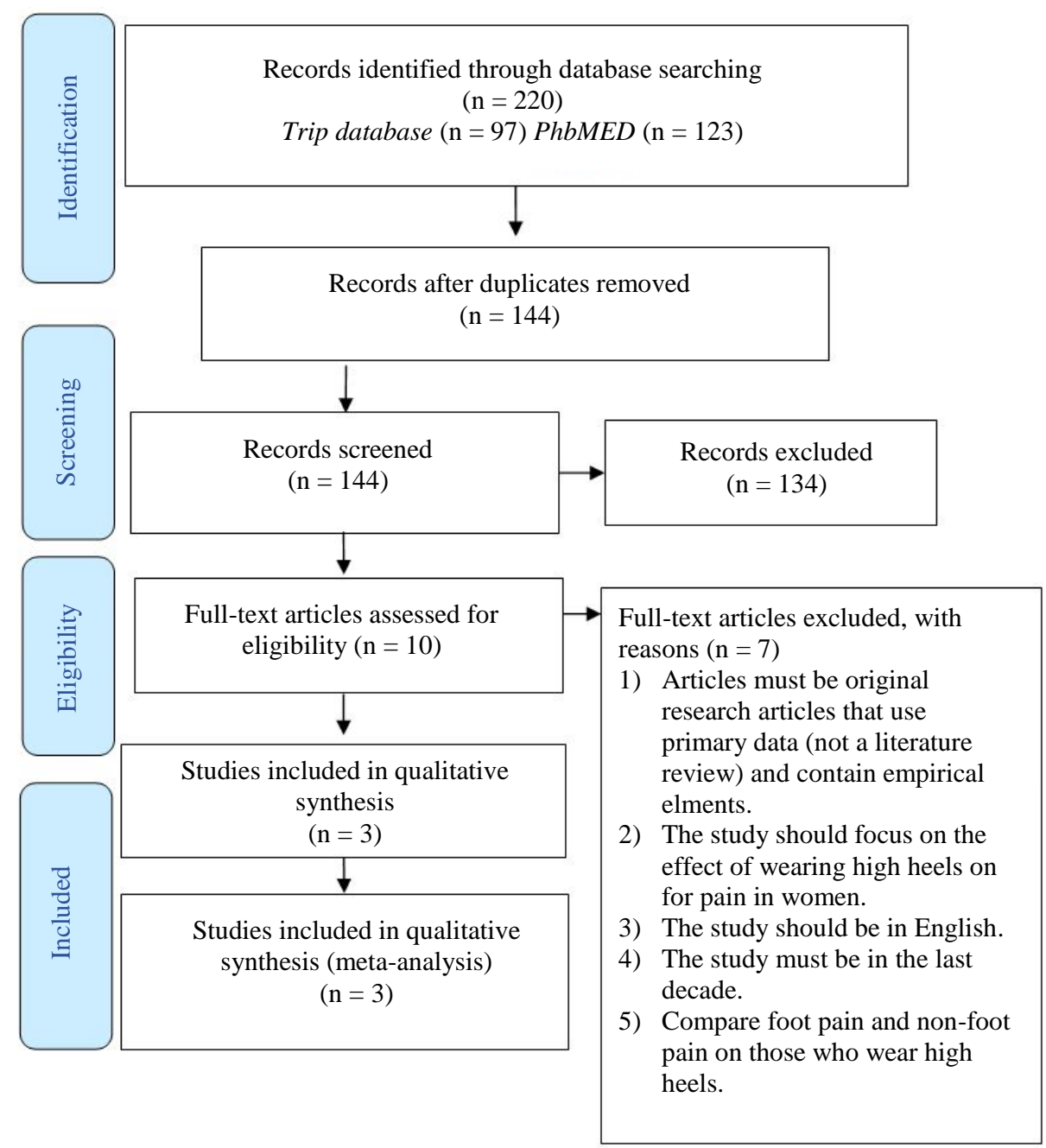

Fig. 1: Flow chart prism of systematic literature searching steps

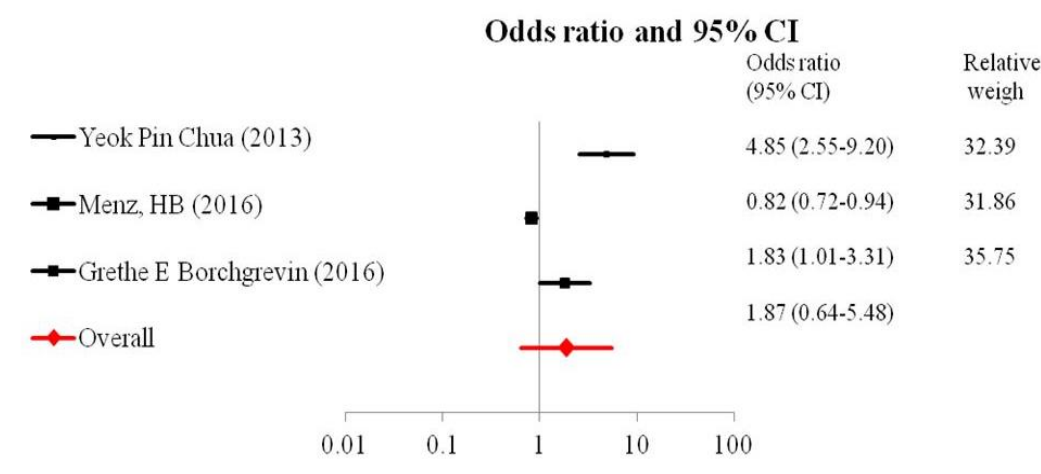

Heterogeneity $(\mathrm{I} 2=94 \%, p=0,000)$

Overall ( $p=0,248$; Random effects model)

Fig. 2: Effect of use of high heels on foot pain

Among these three studies, two studies show foot pain areas due to using high heels. In the literature
(Borchgrevink et al., 2016), the areas with frequent pain on feet were toes $(p=0.04)$ and the middle of the sole 
$(\mathrm{p}=0.02)$. Approximately 49, 25 and $24 \%$ of subjects in the study (Chua et al., 2013) complained of pain on the heel, in the ball of foot/metatarsal head and the middle of the sole, respectively

The results of a meta-analysis study in three studies obtained p combined effect of 0.248 with a combined effect value of 1.87 (0.64-5.48). Thus, the use of high heels on foot pain is not statistically significant, yet clinically the odds ratio result of 1.87 , which means that women who wear high heels have a risk of 1.87 times more likely to have foot pain (Fig. 2).

\section{Discussion}

In this meta-analysis, $I^{2}$ heterogeneity obtained $94 \%$ and $p$ heterogeneity value of 0.000 , which shows these three studies were heterogeneous. This heterogenicity obtained because the studies had different weights and results. In the study of Menz et al. (involving 2,627 subjects), the result was not statistically significant. Meanwhile, two other studies (involving only 197 and 400 subjects) got statistically significant results. Study subjects are directly proportional to the study weight; the higher the study subject, the greater the study weight. The weight of this study will distinguish between average calculations and meta-analysis. In the meta-analysis, the calculation of combined effects by calculating weights, each study's value multiplied by the weights then divided by the total weights. Therefore, the use of high heels in women was not statistically significant with foot pain.

Our study supported the study done by (de Castro et al., 2010) on 227 women and 172 older men. They stated that the use of high heels did not correlate with foot pain $(p=0.351)$. High heels have many types, such as wedge and stiletto heels. Each type of high heels has a different potential to affect the feet biomechanics because they have different contact areas on the floor and feet. High heels can affect the load transmission on foot or even worst people balanced. Shoes that do not have an insole as a cushion on toes and the middle of the foot will provide a different level of constraints on the foot movement within the shoe than shoes that do (Melvin, 2014). Plantar pressure on the use of high heels is inversely proportional to the sole area (contact area) of shoes and the floor through the applied force; the smaller sole area of the shoes the enormous plantar pressure got with the same force (Giancoli, 2004; Barnish and Barnish, 2016).

Based on (López-López et al., 2018) research, 120 research subjects show that women who use high heels will decrease their quality of life due to leg pain complaints. High heels' use impacts foot pain in line with the windlass mechanism theory (the toes bring to dorsiflexion and plantar fascia tightens). The use of high heels itself can increase toe dorsiflexion and increase the firmness in the plantar fascia. A stiff plantar fascia will shorten the calcaneus and the metatarsal distance and lift the medial longitudinal arch. In a high curved position, there is little strain on the plantar fascia so that it can cause irritation, inflammation and micro-tears in the plantar fascia near the calcaneus so that can cause pain in the plantar part of the foot (Bolgla and Malone, 2004; Melvin, 2014; Rosenbaum et al., 2014).

This meta-analysis study also found that women who wore high heels were 1.87 times more likely to have foot pain, especially on the heel and ball of foot/metatarsal head. Foot pain occurs because high-heeled shoes increase the ankle plantarflexion angle and increase pressure on the anterior foot in static (standing) and dynamic (walking) positions. In heel strike situation, those who wear high heels experience an enormous plantar pressure, whereas in push-off plantar pressure increases in the anterior part of the foot or the Metatarsophalangeal Part (MTP) and the first MTP to get the most pressure (Yu et al., 2013; Sylvia, 2018). Plantar pressure on the first MTP or medial front due to the increased plantar pressure when walking in high heels can cause the deformation of hallux valgus (Ran et al., 2016).

In another study, during a static position, a significant height of shoe heels gave different pressure results on each foot area $(p=0.001)$ (Hapsari et al., 2014). Higher heel height can transfer pressure from the heel to the forefoot. The most significant increase in pressure in the prior MTP area can cause the hallux valgus' deformation (Hapsari et al., 2014; Melvin, 2014). Walking for one hour using high heels will change pressure distribution on the feet soles and the center of pressure (Ko and Lee, 2013). Pressure changes mainly occur in a shift in pressure from the hindfoot to the forefoot (Speksnijder et al., 2005). The increased pressure on the forefoot can increase 4.5-4.8 times greater at the middle foot and 2.3-2.5 times on the rear foot when using high heels (Song et al., 2009).

\section{Strengths and Limitations of the Study}

The author realizes that this research has limitations because the review literature process did not involve other reviewers. However, the writer used triangulation by conducting in-depth interviews with experts so that the data truly represents various expert perspectives. Due to the time limit, this author only involves two experts. The author realizes that the more experts involved will undoubtedly provide more comprehensive input. Variations of high heels and the shape of the high heels bring to the heterogeneous data results. If the mentioned aspects can be standardized (height and design of heels) in further epidemiological research, the results may be better. 


\section{Suggestion:}

- Further research is needed to be conducted on whether there is an effect between high heels and foot pain with the cohort study and look at the foot's radiological features for anatomical abnormalities

- Determination of standards in evaluating high heels, the design of high heels and the type of heels are needed to avoid heterogeneous data results

\section{Conclusion}

This meta-analysis study did not show that wearing high heels will cause foot pain in women. Nevertheless, women who use high heels have a higher risk of suffering foot pain.

\section{Acknowledgment}

We acknowledge Universitas Bengkulu.

\section{Author's Contributions}

Anisa Ferli Yolanda: Conceptualized and designed the study, performed the statistical analysis, drafted the initial manuscript and approved the final manuscript as submitted.

Swandito Wicaksono: Designed the study, drafted the initial manuscript.

Ahmad Azmi Nasution: Conceptualized and designed the study, performed the statistical analysis, drafted the initial manuscript and approved the final manuscript as submitted.

\section{Ethics}

This article is original and contains unpublished material. The corresponding author confirms that all of the other authors have read and approved the manuscript and no ethical issues involved.

\section{References}

Barnish, M. S., \& Barnish, J. (2016). High-heeled shoes and musculoskeletal injuries: a narrative systematic review. BMJ Open, 6(1).

Benvenuti, F., Ferrucci, L., Guralnik, J. M., Gangemi, S., \& Baroni, A. (1995). Foot pain and disability in older persons: An epidemiologic survey. Journal of the American Geriatrics Society, 43(5), 479-484.

Bolgla, L. A., \& Malone, T. R. (2004). Plantar fasciitis and the windlass mechanism: A biomechanical link to clinical practice. Journal of athletic training, 39(1), 77.
Borchgrevink, G. E., Viset, A. T., Wits $\varnothing$, E., Schei, B., \& Foss, O. A. (2016). Does the use of high-heeled shoes lead to fore-foot pathology? A controlled cohort study comprising 197 women. Foot and Ankle Surgery, 22(4), 239-243.

Buldt, A. K., \& Menz, H. B. (2018). Incorrectly fitted footwear, foot pain and foot disorders: a systematic search and narrative review of the literature. Journal of foot and ankle research, 11(1), 43.

Chua, Y. P., Tan, W. J., Yahya, T. S. T. A., \& Saw, A. (2013). Prevalence of nontraumatic foot pain among urban young working women and its contributing factors. Singapore Med J, 54(11), 630-633.

de Castro, A. P., Rebelatto, J. R., \& Aurichio, T. R. (2010). The relationship between foot pain, anthropometric variables and footwear among older people. Applied ergonomics, 41(1), 93-97.

Edwards, L., Dixon, J., Kent, J. R., Hodgson, D., \& Whittaker, V. J. (2008). Effect of shoe heel height on vastus medialis and vastus lateralis electromyographic activity during sit to stand. Journal of orthopaedic surgery and research, 3(1), 2.

Ghiftama, S., \& Hakim, P. (2019). Sistem Interchangeable pada Sepatu Wanita. Jurnal Desain Idea: Jurnal Desain Produk Industri Institut Teknologi Sepuluh Nopember Surabaya, 18(1), 25-30.

Giancoli, D. C. (2004). Physics: principles with applications. Upper Saddle River, NJ: Pearson Education.

Hapsari, V. D., Xiong, S., \& Yang, S. (2014, September). High heels on human stability and plantar pressure distribution: Effects of heel height and shoe wearing experience. In Proceedings of the Human Factors and Ergonomics Society Annual Meeting (Vol. 58, No. 1, pp. 1653-1657). Sage CA: Los Angeles, CA: SAGE Publications.

Ko, D. Y., \& Lee, H. S. (2013). The changes of COP and foot pressure after one hour's walking wearing highheeled and flat shoes. Journal of physical therapy science, 25(10), 1309-1312.

López-López, D., Marañon-Medina, J., Losa-Iglesias, M. E., Calvo-Lobo, C., Rodríguez-Sanz, D., PalomoLópez, P., \& Vallejo, R. B. D. B. (2018). The influence of heel height related on quality of life on the foot in a sample of women. Revista da Associação Médica Brasileira, 64(4), 324-329.

Maarouf, M. A. (2015). The impact of wearing high heels on women's health and attractiveness: a field study. J Basic Appl Sci Res, 5(8), 54-61.

Melvin, J. M. (2014). The effects of heel height, shoe volume and upper stiffness on shoe comfort and plantar pressure (Doctoral dissertation, University of Salford). 
Menz, H. B., Roddy, E., Marshall, M., Thomas, M. J., Rathod, T., Peat, G. M., \& Croft, P. R. (2016). Epidemiology of shoe-wearing patterns over time in older women: associations with foot pain and hallux valgus. Journals of Gerontology Series A: Biomedical Sciences and Medical Sciences, 71(12), 1682-1687.

Ran, M., Hao, F., Yang, L., \& Wu, S. (2016). 'Effects of high heels on centre of pressure progression during walking in young women', Leather and Footwear Journal, 16(1), 29-42.

Rao, S., Riskowski, J. L., \& Hannan, M. T. (2012). Musculoskeletal conditions of the foot and ankle: assessments and treatment options. Best Practice \& Research Clinical Rheumatology, 26(3), 345-368.

Rosenbaum, A. J., DiPreta, J. A., \& Misener, D. (2014). Plantar heel pain. Medical Clinics, 98(2), 339-352.

Song, J. W., Kim, S. J., Lee, G. H., Song, K. B., \& Kong, Y. K. (2009). Evaluation of foot pressures and subjective discomfort ratings associated with sneakers, high heels and kill heels. Journal of the Ergonomics Society of Korea, 28(3), 95-102.
Speksnijder, C. M., vd Munckhof, R. J., Moonen, S. A., \& Walenkamp, G. H. (2005). The higher the heel the higher the forefoot-pressure in ten healthy women. The foot, 15(1), 17-21.

Stewart, W. F., Ricci, J. A., Chee, E., Morganstein, D., \& Lipton, R. (2003). Lost productive time and cost due to common pain conditions in the US workforce. Jama, 290(18), 2443-2454.

Sylvia, A. (2018). A Biomechanical Examination of the Lower Extremities in High Heeled Shoes.

Yu, J., Cheung, J. T. M., Wong, D. W. C., Cong, Y., \& Zhang, M. (2013). Biomechanical simulation of high-heeled shoe donning and walking. Journal of biomechanics, 46(12), 2067-2074. 